\title{
Influence of Dodecylbenzene Sulfonic Acid Doping on Structural, Morphological, Electrical and Optical Properties on Polypyrrole/3C-SiC Nanocomposites
}

\author{
Sacchidanand Shrikrushna ${ }^{1 *}$, Jayant A Kher ${ }^{1}$ and Milind V Kulkarni ${ }^{2}$ \\ ${ }^{1}$ Department of Applied Sciences, College of Engineering, Pune, Maharashtra, India \\ ${ }^{2}$ Nanocomposite Laboratory, Centre for Materials for Electronics Technology, Pune, Maharashtra, India
}

\begin{abstract}
Dodecylbenzene sulfonic acid (DBSA) doped nanocomposites of Polypyrrole-silicon carbide (PPy-SiC) were synthesized via insitu chemical oxidation polymerization of Pyrrole act as monomer. Dodecylbenzene sulfonic acid and Iron (III) chloride were used as a dopant and oxidization agent, respectively. The molar ratio of monomer unit to oxidization agent was 1:2.4. These nanocomposites were characterized for their structure, thermal stability, surface morphology and DC electrical conductivity by UV-Visible spectroscopy, FT-IR, XRD, TGA, SEM and four-probe method respectively. The electrical property of chemically prepared Polypyrrole and Polypyrrole/SiC in aqueous solution was found to be strongly depending on doping material, oxidant and solvent. It obeys Ohm's Law and convincing applies for battery technology and sensor applications.
\end{abstract}

Keywords: Polypyrrole; Electrical conductivity; Dodecylbenzene sulfonic acid; 3C-SiC; Nanocomposite

\section{Introduction}

'Pyrrole Black' is readily obtained in its conducting form by chemical or electrochemical oxidation of Pyrrole. Chemical synthesis of Polypyrrole yields a conducting polymer that incorporates the anion as counter ion, which electrically neutralizes the partially charged polymer chain [1]. It has been noticed that the conductivity of Polypyrrole film is highly dependent on the nature of the anions in the polymerization solution. Silicon carbide $(\mathrm{SiC})$ is a wide-band gap semiconductor material show signs of mechanical and electrical properties suitable for formulating devices for use in high temperature. Silicon carbide can subsist in many different crystal arrangements depending on growth conditions, a phenomenon called polytypism. Polytypism is an unusual case of polymorphism, in which the crystal structures between two polymorphs are at variance only in the way indistinguishable, two-dimensional layers of close-packed layers are heap. Early 1900s, conducting polymers reported as 'aniline black' and 'Pyrrole black' conducting polymers, on the other hand, differ greatly from these insulating polymers because, as their name suggests, they are intrinsically conducting [2]. The development of these polymers is largely due to the Conducting polymers can be easily synthesized by both chemical and electrochemical routes $[3,4]$ and preparation of various polymers in both aqueous and non aqueous solutions has been reported [5]. In this work, synthesis, characterization of Dodecylbenzene sulfonic acid Doped Polypyrrole/3C-SiC nanocomposites and study of their thermal and electrical property studied.

\section{Experimental}

\section{Materials}

Pyrrole monomer was double distilled before use. Silicon Carbide, Dodecylbenzene sulfonic acid (DBSA) were purchased from Sigma Aldrich and used as received. Distilled water was used for preparation of all aqueous solutions.

\section{Synthesis of polypyrrole}

$1 \mathrm{H}$-Pyrrole monomer (1M, $6.7 \mathrm{gm})$ after double distilled was oxidized with $(2.4 \mathrm{M})$ of aqueous solution of Iron (II) chloride under continuous stirring for $12 \mathrm{~h}$. The complete polymerization was carried out for $12 \mathrm{~h}$ at $0-5^{\circ} \mathrm{C}$ in an ice-salt bath under stirring. The resulting black precipitates were filtered under vacuum. Finally a dark powder of PPy obtained was dried in oven at $50^{\circ} \mathrm{C}$. The yield of PPy was $89 \%$.

\section{Synthesis of DBSA doped polypyrrole-SiC nanocomposites}

The synthesis of DBSA doped PPy-SiC nanocomposites mainly involved (1M) Pyrrole monomer was mixed with fine silicon carbide powder in the presence of aqueous solution of Dodecylbenzene sulfonic acid under continuous stirring for $1 \mathrm{~h}$ to obtain a uniform emulsion. Reaction mixture was kept in ultrasonic bath for $30 \mathrm{~min}$. (2.4M) of aqueous solution of Iron (II) chloride added to the above mixture to start polymerization under continuous stirring for $12 \mathrm{~h}$ at $0-5^{\circ} \mathrm{C}$ in an ice-salt bath. After polymerization, the product was filtered and washed with excess of de-ionized water, ethanol for several times to remove unreacted dopant, oxidant and monomer species. Finally dark powder of DBSA doped PPy-SiC nanocomposites was obtained which further dried under vacuum.

\section{Instrumentation}

UV-Vis spectra of the nanocomposites were obtained with a LAB INDIA $3000+$ UV-Vis spectrophotometer using $\mathrm{m}$-cresol as solvent. FT-IR spectra of nanocomposites pellets were obtained on a FT-IR spectrometer. Scanning electron microscopy (FE-SEM), TGA, four probe setup was used to determine morphology, thermal loss and electrical conductivity respectively.

*Corresponding author: Sacchidanand Shrikrushna, Department of Applied Sciences, College of Engineering, Pune, Maharashtra, India, Tel: 02025507000; E-mail: shrivigraha@gmail.com

Received July 27, 2015; Accepted September 05, 2015; Published October 01 2015

Citation: Shrikrushna S, Kher JA, Kulkarni MV (2015) Influence of Dodecylbenzene Sulfonic Acid Doping on Structural, Morphological, Electrical and Optical Properties on Polypyrrole/3C-SiC Nanocomposites. J Nanomed Nanotechnol 6: 313 doi:10.4172/2157-7439.1000313

Copyright: (c) 2015 Shrikrushna SA, et al. This is an open-access article distributed under the terms of the Creative Commons Attribution License, which permits unrestricted use, distribution, and reproduction in any medium, provided the original author and source are credited. 


\section{Characterizations}

\section{UV-VIS analysis}

LABINDIA UV 3000. Operated at room temperature. PPy display absorption peak at $446 \mathrm{~nm}$ which are in support with literature values [6].

\section{FT-IR analysis}

Bruker FT-IR Spectrophotometer operated at room temperature in the normal IR region $4000-650 \mathrm{~cm}^{-1}$ and $4 \mathrm{~cm}^{-1}$ band resolutions was used for structural analysis [7].

\section{X-ray diffraction analysis}

The X-ray diffraction studies of the samples were done on a Rigaku X-ray Diffractometer with $\mathrm{Cu}-\mathrm{Ka}\left(1.5418 \mathrm{~A}^{\circ}\right)$ radiation operating at $30 \mathrm{kV}$ and $20 \mathrm{~mA}$. Scanning was carried out in the $2 \theta$ range from $10^{\circ}$ to $80^{\circ}$ at a scan speed of $2^{\circ}$ per minute.

\section{SEM analysis}

SIGMA HV Field Emission-Scanning Electron Microscope (FESEM) was used for microstructure analysis. It was operated at back scattered electron image mode. Before observations, the samples were sputtered for $15 \mathrm{~min}$. and mounted on an aluminum stub with conductive silver paint so that no gas in vacuum chamber.

\section{Thermal gravimetric analysis}

TGA analysis was performed by SDT Q600. The calorimeter cell was flushed with $100 \mathrm{~mL} \mathrm{~min}{ }^{-1}$ of nitrogen. An aluminum pan was used as a reference. The runs were performed from room temperature to $1050^{\circ} \mathrm{C}$ with a heating rate of $10^{\circ} \mathrm{C} / \mathrm{min}$.

\section{Electrical conductivity}

DC electrical conductivity of samples was measured by standard four-probe technique at room temperature $\left(25^{\circ} \mathrm{C}\right)$. Compressed pellets (Diameter-15 mm) of materials were made under hydraulic pressure of 10 tones by using Kimaya Engg. Hydraulic press.

\section{Results and Discussion}

\section{UV-VIS analysis}

Figure 1 represents the UV-Vis spectra of $\mathrm{PPy}$ and $\mathrm{PPy} / \mathrm{SiC}$

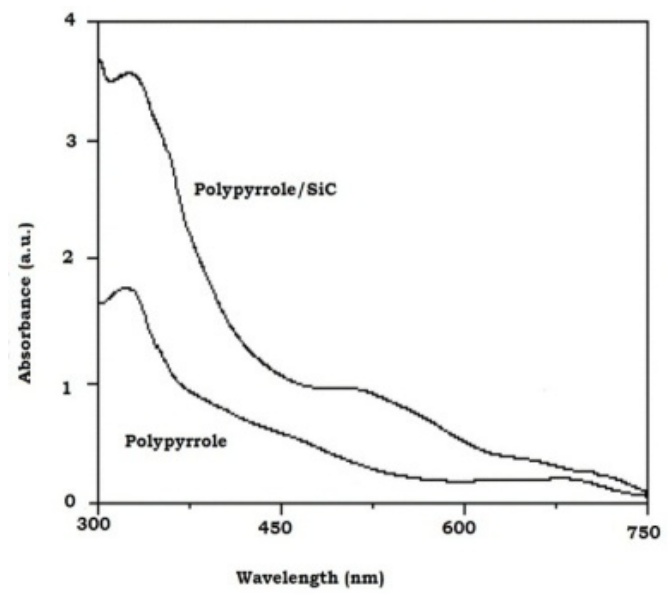

Figure 1: UV-vis spectra of PPy and PPy/SiC composite.

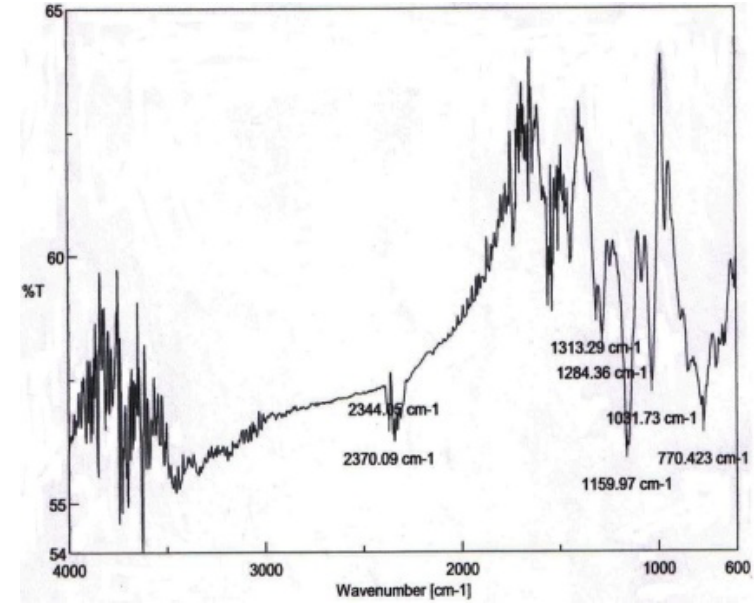

Figure 2: FT-IR absorption spectra of pure PPy.

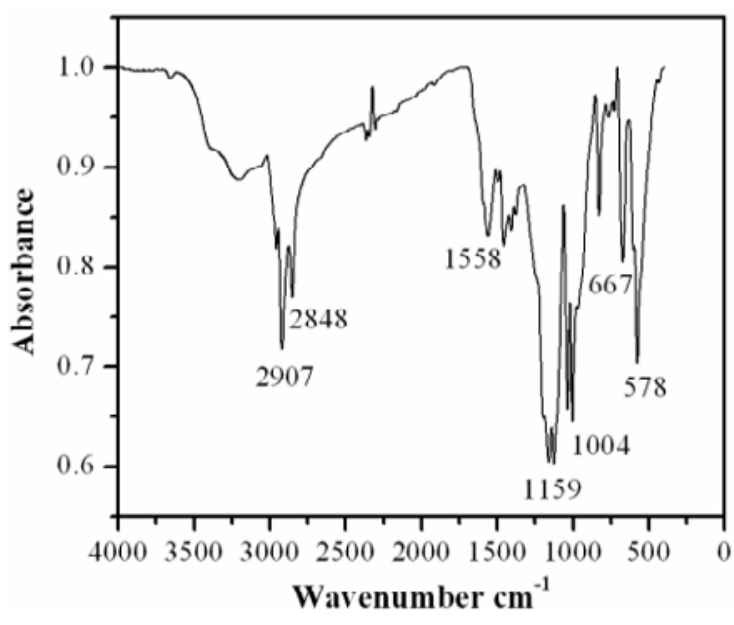

Figure 3:FT-IR absorption spectra of DBSA dope PPy/SiC.

exhibit absorption peak at $326 \mathrm{~nm}$ and $330 \mathrm{~nm}$ respectively reveals $\pi \rightarrow \pi^{*}$ transition in benzenoid rings of DBSA [8]. The band $520 \mathrm{~nm}$ is associated with the transition from the valence band to the antibonding polaron state.

\section{FT-IR analysis}

Figures 2 and 3 represents the FT-IR spectra of pure PPy and DBSA dope $\mathrm{PPy} / \mathrm{SiC}$ nanocomposite respectively. The band at $1558 \mathrm{~cm}^{-1}$ and a weak band at $1468 \mathrm{~cm}^{-1}$ are assigned to stretching vibration of $\mathrm{C}=\mathrm{C}$ and $\mathrm{C}-\mathrm{C}$ in the Pyrrole ring [9-11]. The absorption at $1284 \mathrm{~cm}^{-1}$ corresponds to $\mathrm{C}-\mathrm{H}$ in plane deformation modes [12-14]. PPy shows characteristic $\mathrm{C}-\mathrm{N}$ and $\mathrm{C}-\mathrm{H}$ stretching vibration of Pyrrole at1159 $\mathrm{cm}^{-1}$ and $1031 \mathrm{~cm}^{-1}$ respectively in the infrared spectrum [13]. The band observed at $1004 \mathrm{~cm}^{-1}$ and $676 \mathrm{~cm}^{-1}$ maybe recognized to the out of plane ring deformation and to the $\mathrm{N}-\mathrm{H}$ vibrations in polymer [13]. The band at $2907 \mathrm{~cm}^{-1}, 1558 \mathrm{~cm}^{-1}, 1159 \mathrm{~cm}^{-1}$, is assigned to $\mathrm{C}-\mathrm{H}$ stretch (strong), $\mathrm{N}-\mathrm{H}$ bending vibration of $\mathrm{C}=\mathrm{C}$ and $\mathrm{C}-\mathrm{C}$ in the Pyrrole ring, $\mathrm{C}-\mathrm{N}$ stretch, confirming the Polypyrrole formation [15]. Frequencies and their assignment of DBSA doped PPy-SiC nanocomposite is described in Table 1.

\section{$\mathrm{X}$-ray diffraction (XRD) analysis}

The XRD patterns of the PPy sample are shown in Figure 4. The 
Citation: Shrikrushna S, Kher JA, Kulkarni MV (2015) Influence of Dodecylbenzene Sulfonic Acid Doping on Structural, Morphological, Electrical and Optical Properties on Polypyrrole/3C-SiC Nanocomposites. J Nanomed Nanotechnol 6: 313. doi:10.4172/2157-7439.1000313

Page 3 of 5

\begin{tabular}{|c|c|}
\hline $\begin{array}{c}\text { Wave number } \\
\left(\mathbf{c m}^{-1}\right)\end{array}$ & \begin{tabular}{c} 
Assignment \\
\hline 2907
\end{tabular} \\
\hline 2848 & $\mathrm{C}-\mathrm{H}$ stretch (strong) \\
\hline 1558 & Five member ring $\mathrm{C}-\mathrm{H}$ stretching \\
\hline 1284 & $\mathrm{~N}-\mathrm{H}$ bending vibration of $\mathrm{C}=\mathrm{C}$ and $\mathrm{C}-\mathrm{C}$ in the pyrrole ring \\
\hline 1313 & $\mathrm{C}-\mathrm{N}$ stretching mode of vibration \\
\hline 1159 & $\mathrm{C}-\mathrm{H}$ in plane deformation of the Polypyrrole and $\mathrm{N}-\mathrm{H}$ bending \\
\hline 1031 & Aromatic $\mathrm{C}-\mathrm{H}_{\text {in plane bending vibration }}$ \\
\hline 667 & $\mathrm{SO}_{3}-$ vibration \\
\hline 770 & Fundamental vibration mode of $\mathrm{SO}_{4}$ \\
\hline
\end{tabular}

Table 1: Characteristic frequencies of DBSA doped PPy-SiC nanocomposites.

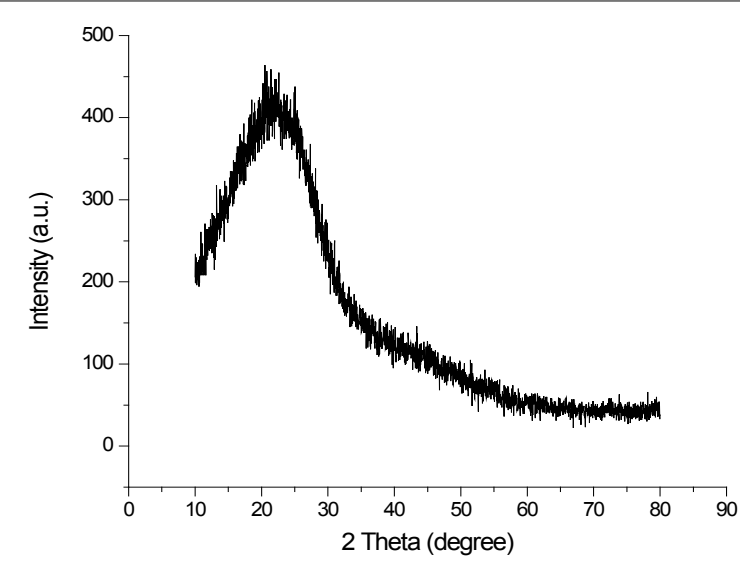

Figure 4: XRD patterns of Polypyrrole.

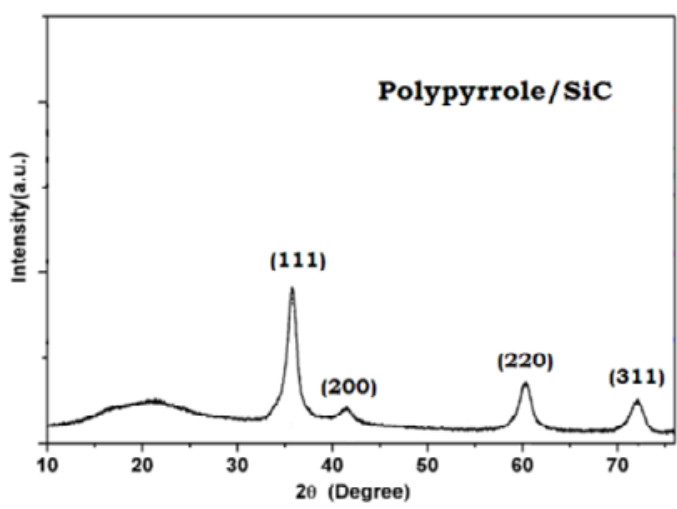

Figure 5: XRD patterns of Polypyrrole/SiC composites.

PPy-SiC and DBSA dope PPy-SiC nanocomposites shows exceptionally higher crystalline compared to the undope samples Figures 5 and 6. X-ray diffraction studies show that the Polypyrrole powder is amorphous in nature. Figure 5 indicate that the pure Polypyrrole broad peak presented by peak $2 \theta=20.530$ is due to PPy existence $[16,17]$.

The crystal planes spacing is calculated using the Bragg's equation $\mathrm{n} \lambda=2 \mathrm{~d} \sin \theta$, where $n$ is an integer determined by the order given, $\lambda$ is the wavelength of the $\mathrm{Cu} K a$ radiation source $(\lambda) 1.5406 \mathrm{~A}^{\circ}$, and $\theta$ is the angle between the incident ray and the scattering planes [18]. The XRD patterns of the Silicon carbide nanoparticles in Polypyrrole matrix. Figure 6 can be seen clearly that the samples consist of crystalline phases presented by four main diffraction peaks at $2 \theta=36.110,42.290$, 60.480 , and 72.470 that correspond to the lattice planes (111), (200),
(220), and (311). Dodecylbenzene sulfonic acid doped Polypyrrole silicon carbide composites shows similar but very sharp peaks hence uniformly distributed in polymer matrix (Figure 6). The XRD patterns show that the silicon carbide is (3C-SiC) type and crystal structure of the sample is Face centered cubic was confirmed by JCPDS file no. 291129.

\section{Scanning electron microscopy (SEM) analysis}

Scanning electron micrograph of chemically synthesized Polypyrrole has shown mostly the growth in the bulbous porous form but changes due to dopant molecules. Typical SEM images of Polypyrrole are shown in Figures 7a and 7b. Each and every one SEM image shows a globular porous structure and it was observed that individual granules were nearly spherical and has a close packing [19]. It was shown that such spherulites are growing over the other and forming a continuous structure. SEM micrographs of $\mathrm{PPy} / \mathrm{SiC}$ and DBSA dope $\mathrm{PPy} / \mathrm{SiC}$ composites are shown in Figures $7 \mathrm{c}-\mathrm{f}$. All micrographs reveal complete encapsulation of $\mathrm{SiC}$ particles in PPy matrix and agglomeration of grains having spherical morphology with diameter in the range of 68$276 \mathrm{~nm}$.

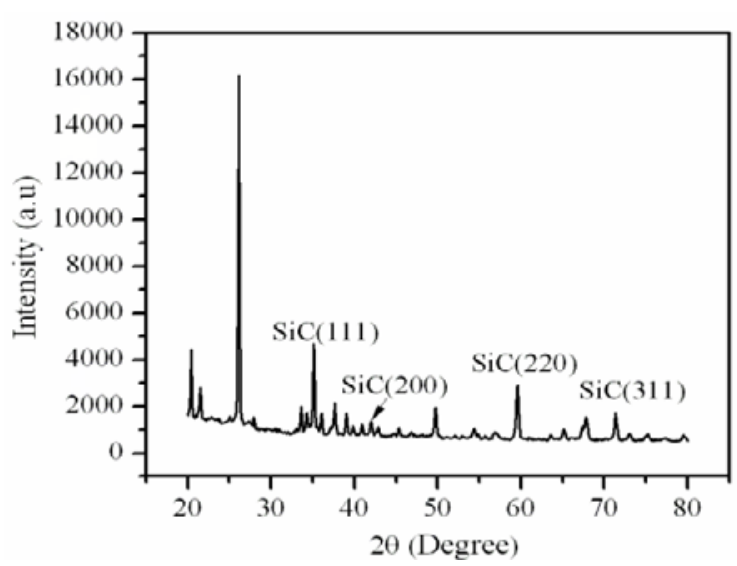

Figure 6: XRD patterns of DBSA doped Polypyrrole/Si Cnano composites.

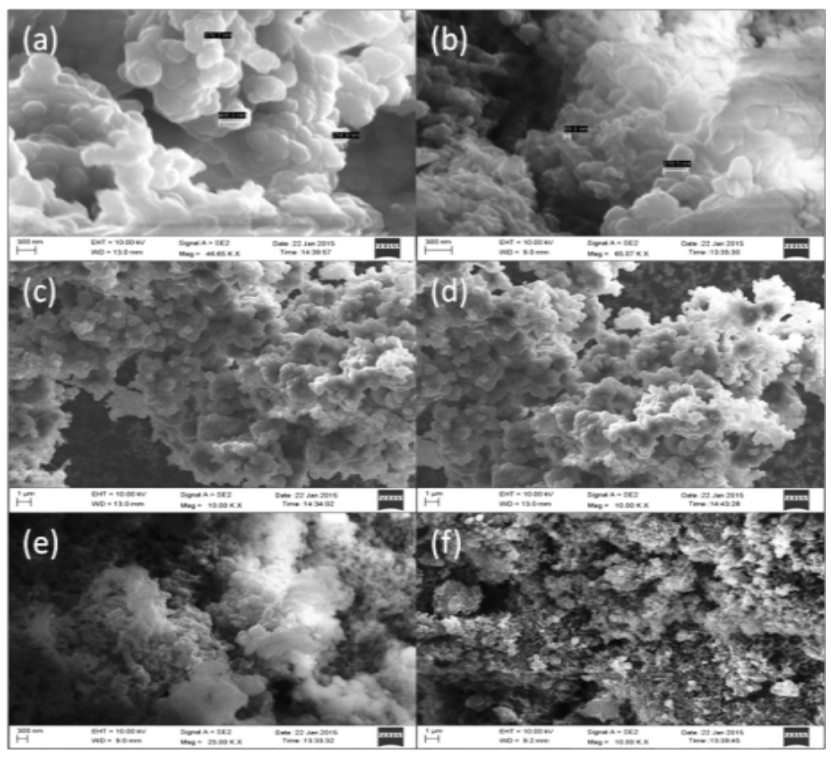

Figure 7: (a,b) SEM patterns of Polypyrrole; (c,d) SEM patterns of PPy/ $\mathrm{SiC} ;(\mathbf{e}, \mathbf{f})$ SEM patterns of DBSA doped PPy-SiC. 
Citation: Shrikrushna S, Kher JA, Kulkarni MV (2015) Influence of Dodecylbenzene Sulfonic Acid Doping on Structural, Morphological, Electrical and Optical Properties on Polypyrrole/3C-SiC Nanocomposites. J Nanomed Nanotechnol 6: 313. doi:10.4172/2157-7439.1000313

Page 4 of 5

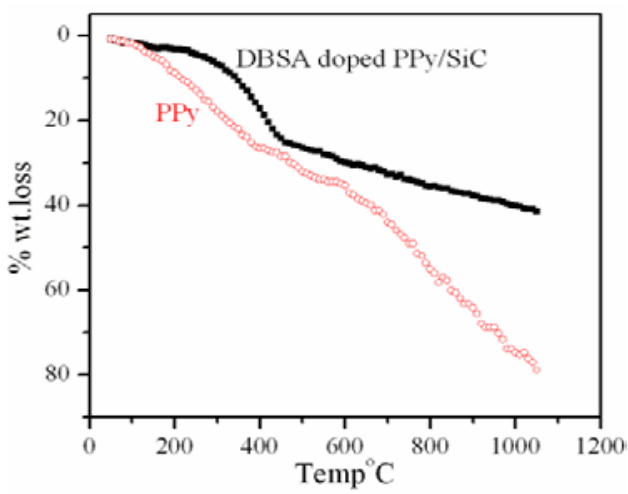

Figure 8: TG Analysis of PPy and DBSA dope PPY/SiCnanocomposites.

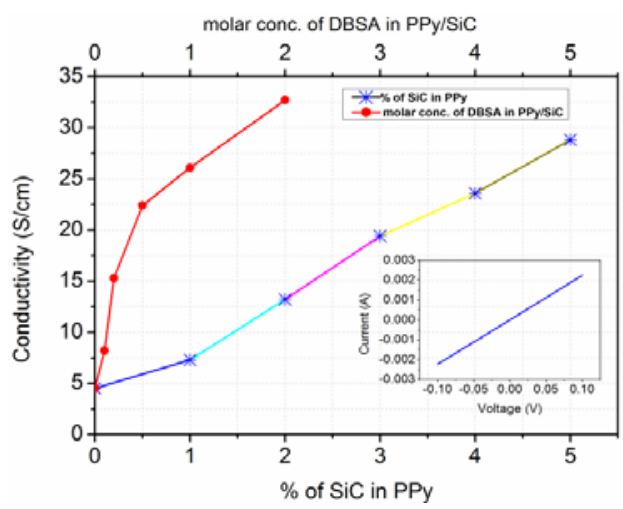

Figure 9: varying conductivity with \% of $\mathrm{SiC}$ in PPyand molar concentartion of DBSA in PPy/SiC.

\begin{tabular}{|l|c|c|c|c|}
\hline Sr. No & \% of SiC in PPy & $\begin{array}{c}\text { Conductivity (S/ } \\
\mathbf{c m})\end{array}$ & $\begin{array}{c}\text { DBSA doping } \\
\text { PPy-SiC in mole }\end{array}$ & $\begin{array}{c}\text { Conductivity (S/ } \\
\mathbf{c m})\end{array}$ \\
\hline 1 & 0 & 4.5 & 0 & 4.5 \\
\hline 2 & 1 & 7.3 & 0.1 & 8.2 \\
\hline 3 & 2 & 13.2 & 0.2 & 15.3 \\
\hline 4 & 3 & 19.4 & 0.5 & 22.4 \\
\hline 5 & 4 & 23.6 & 1 & 26.1 \\
\hline 6 & 5 & 28.8 & 2 & 32.7 \\
\hline
\end{tabular}

Table 2: Effect of DBSA doping on PPy/SiC nanocomposites.

\section{Thermal Gravimetric Analysis (TGA)}

Figure 8 flaunts the thermal gravimetric analysis of PPY and DBSA doped PPY/SiC nanocomposite under $\mathrm{O}_{2}$ atmospheres. It reveal that the thermal stability of DBSA doped PPY $\backslash \mathrm{SiC}$ is much higher than that of PPy in the temperature range of $30-1050^{\circ} \mathrm{C}$. Due to the evaporation of residual water molecules, nearly $10 \mathrm{wt} \%$ weight loss of PPY has occurred at $200^{\circ} \mathrm{C}$ while only $2 \mathrm{wt} \%$ weight losses for DBSA dope $\mathrm{PPy} / \mathrm{SiC}$ nanocomposites. The main mass loss of PPy and PPy/ $\mathrm{SiC}$ nanocomposites starts at about $300^{\circ} \mathrm{C}$ corresponding to $\mathrm{PPy}$ degradation as the temperature elevate. Finally at $1050^{\circ} \mathrm{C}$ temperature, $80 \%$ weight loss of PPY is much more than DBSA doped PPY/SiC nanocomposites (40\%).

\section{DC conductivity measurements}

The electrical conductivities of PPy, PPy/SiC and DBSA dope PPy/ $\mathrm{SiC}$ nanocomposites are determined using a Digital AC milivoltmeter four point probe resistivity measurement system. It is observed that the room temperature electrical conductivity of Polypyrrole is $4.5 \mathrm{~S} /$ $\mathrm{cm}$ shown in Figure 9. PPy/SiC shows a conductivity of $(28 \mathrm{~S} / \mathrm{cm})$ and DBSA doped $\mathrm{PPy} / \mathrm{SiC}$ give high value of conductivity depend upon doping concentration [20]. Table 2 shows the variation of electrical conductivity $(\sigma)$ with increasing doping concentration of DBSA into $\mathrm{PPY} / \mathrm{SiC}$ measured at the slower rate according to the standard four point probe method at room temperature.

\section{Conclusions}

In summary, we were able to prepare $\mathrm{PPy}, \mathrm{PPy} / \mathrm{SiC}$ and DBSA dope $\mathrm{PPy} / \mathrm{SiC}$ nanocomposite particles by direct oxidation of Pyrrole with unhydrous ferric chloride by insitu-chemical polymerization. The processability of Polypyrrole/silicon carbide composites improved with increasing content of dopant. The UV-Vis absorption spectra showed $\pi \rightarrow \pi^{*}$ transition in benzenoid rings of DBSA. FTIR study confirmed the presence of dopant in the composite structure. The fine and sharp XRD peaks were observed after doping with DBSA. The particle size distribution of $\mathrm{PPy}, \mathrm{PPy} / \mathrm{SiC}$ and DBSA doped PPY/SiC composites were found at $67-276 \mathrm{~nm}$. The SEM study showed the granular morphology and aggregation of particles with higher concentration of dopant. It was observed that the conductivity of Polypyrrole composite increases with increasing wt $\%$ of $\mathrm{SiC}$ as well as molar concentration of DBSA and IV analysis gives linear pitch curve. The results suggest that the PPY/SiC prepared in the presence of DBSA has ohmic conducting property and better thermal stability.

\section{Acknowledgments}

This research is supported by Division of Physical and Mathematical Sciences, Indian Institute of Science, Bangalore. The researcher named Sacchidanand Shrikrushna would like to thank TEQIP-DTE-Maharashtra for its financial support.

\section{References}

1. Nagels GT, Winard R, Weymeersch A, Renard L (1992) Electron conducting organic coating of mild steel by electropolymerization. J Appl Electrochem 22 756-764.

2. Kang HC, Geckeler KE (2000) Enhanced electrical conductivity of polypyrrole prepared by chemical oxidative polymerization: effect of the preparation technique and polymer additive. Polymer 41: 6931-6934.

3. Diaz AF, Bargon J (1986) In Handbook of Conducting Polymers Skotheim TA Marcel Dekker 1: 81- 116.

4. Shirakawa H (1998) In Handbook of Conducting Polymers; Skotheim TA Elsenbaumer RL, Reynolds JR, (Eds.), Marcel Dekker.197-208.

5. Visy C, Lukkari J, Kankare J (1993) Macromolecules 27: 3322

6. Wang ZL, Kong XY, Ding Y, Gao P, Hughes WL, et al. (2004) Semiconducting and Piezoelectric Oxide Nanostructures Induced by Polar Surfaces. Advanced Functional Materials 14: 943-956

7. Nabid MR, Entezami AA (2004) A Novel Method for Synthesis of Water-soluble Polypyrrole with Horseradish Peroxidase Enzyme. J Appl Polym Sci 94: 254-258.

8. Lemon P, Haigh J (1999) The evolution of nodular polypyrrole morphology during aqueous electrolytic deposition: Influence of electrolyte gas discharge. $\mathrm{J}$ Materials Research Bulletin 34: 665-672.

9. Sadki S, Schottland P, Brodie N, Sabouraud G (2000) The mechanisms of pyrrole electro polymerization. Chem Soc Rev 29: 283-293.

10. Walker JA, Warren LF, Witucki EF (1988) New chemically prepared conducting "pyrrole blacks". J Polym Sci Part A: Polym Chem 26: 1285-1294.

11. Nardis S, Monti D, Natable CD, Amico AD, Siciliano P, et al. (2004) Sens and Actuators B 103: 339.

12. Kharat HJ, Kakade KP Savale PA, Dutta K, Ghosh P (2007) Synthesis of polypyrrole films for the development of ammonia sensor. Polymers for Advanced Technologies 18: 397- 402

13. Tian B, Zerbi G (2009) Journal of Chemical Physics 92: 3886-3891. 
Citation: Shrikrushna S, Kher JA, Kulkarni MV (2015) Influence of Dodecylbenzene Sulfonic Acid Doping on Structural, Morphological, Electrical and Optical Properties on Polypyrrole/3C-SiC Nanocomposites. J Nanomed Nanotechnol 6: 313. doi:10.4172/2157-7439.1000313

Page 5 of 5

14. Arora K, Singhal R, Singh RP, Chaubey A, Samanta SB, et al. (2006) "Application of Electrochemically Prepared Polypyrrole Polyvinyl Sulphonate Films to DNA Biosensor". Biosensors and Bioelectronics 21: 1777- 1783

15. Hosono K, Matsubara I, Murayama N, Shin W, Izu N (2005) Synthesis of Polypyrrole/ $\mathrm{MoO}_{3}$ Hybrid thin films and their volatile organic Compound GasSensing Properties. Chem Mater 17: 349-354.

16. Shinde SS, Kher JA, Kulkarni MV (2014) International Journal of Innovative Research in Science. Engineering and Technology 3.
17. Rüdel R, Zite-Ferenczy $F$ (1979) Interpretation of light diffraction by crossstriated muscle as Bragg reflexion of light by the lattice of contractile proteins. J Physiol 290: 317-330.

18. Eisazadeh H (2007) Studying the Characteristics of Polypyrrole and its Composites.World Journal of Chemistry 2: 67-74.

19. Depaoli MA, Waltaman RJ (1985) An electrically conductive plastic composite derived from polypyrrole and poly vinyl chloride. Polym Sci Polym Chem 23 1687-1698.

20. Prevost V, Petit A (1999) F Pla Synth Metal 104: 79. 